\title{
Capitalising Experiential Knowledge for Guiding Construction Procurement Selection
}

S. Thomas Ng (Department of Civil Engineering, The University of Hong Kong, Hong Kong), Chris D.T. Luu (Lahey Constructions Pty Ltd., New South Wales, Australia) and R. Martin Skitmore (School of Construction Management and Property, Queensland University of Technology, Brisbane, Australia)

\begin{abstract}
Capitalising useful knowledge for construction procurement selection (CPS) decisions would provide a valuable asset to client organisations, as the successful/unsuccessful experience would help decision-makers avoid the occurrence of similar errors and ensure the most suitable procurement system is employed for a construction project. As a result, there is a need to examine the potential for developing a knowledge management model to capture and reuse experiential knowledge to guide CPS decisions. This paper begins by identifying a suitable approach for managing CPS knowledge. This is followed by a discussion of the knowledge required for CPS decision support. A prototype knowledgemanagement model is developed, using the case-based reasoning (CBR) approach, and a mechanism for the retrieval and reuse of knowledge for guiding CPS decisions is elucidated. The results indicate that $\mathrm{CBR}$ is a suitable tool for formulating the procurement selection parameters and selecting a suitable procurement system for a construction project. This is primarily because the CBR approach is flexible enough to allow closely matching historic cases to be retrieved as well as enabling the decisionmaker to adapt the proposed solution based on the predominant characteristics of the client, project and external environment pertinent to the current project.
\end{abstract}

Keywords: case-based reasoning, construction procurement, knowledge management, procurement selection parameters.

\section{INTRODUCTION}

Industry is becoming more enthusiastic about the use of multifarious alternative construction procurement systems, and choosing an appropriate method of procurement to satisfy the unique client and project requirements is recognised as one of the most important activities involved today (Naoum, 1994; Sharif and Morledge, 1994; Rwelamila and Meyer, 1999). Over the last two decades, researchers have attempted to develop a reliable decision tool for construction procurement selection (CPS). These include the procurement path decision chart (NEDO, 1985); procurement rating (Franks, 1990); multiattribute (Bennett and Grice, 1990; Singh, 1990; Ambrose and Tucker, 1999); multivariate analysis (Chan et al., 2001); multicriteria/multiscreening (Alhazmi and McCaffer, 2000); analytical hierarchical process (Cheung et al., 2001); discriminant analysis (Skitmore and Marsden, 1988); decision support system (Kumaraswamy and Dissanayaka, 2001); and knowledge-based system (Brandon et al., 1988; Mohsini, 1993) models.

Although these research models could improve the transparency and objectiveness of CPS decisions, there are still problems to be resolved before they can become credible enough for practical usage. One major concern is to cater for the implicit interrelationships among the procurement selection parameters (PSPs) and their corresponded importance weightings instigated by diverse client's characteristics and needs, project features, and external environment (Ireland, 1985; Nahapiet and Nahapiet, 1985; Hamilton, 1987). Besides, as there are hardly any hard and fast rules/guidelines, the suitability and likely outcomes of a particular procurement system are hard to envisage. Ward et al. (1991) and Masterman (1992) advocate CPS decisions being realistically founded on experiences of previous similar examples, coupled with intuitive evaluations of the distinctive requirements of the current situation.

However, it would be virtually impossible for decision-makers to acquire and/or recall all the experiential knowledge needed, as there is a diverse continuum of procurement options in practice (Kumaraswamy and Dissanayaka, 2001). Successful or unsuccessful experiences pertinent to each CPS decision should be systematically encapsulated and managed (cf: Storey and Barnett, 2000) to ensure useful knowledge being retrieved for strategic/tactical decision support (Silver, 2000). The concept of knowledge management has been introduced to construction project risk management (Tah and Carr, 2001) and selection of construction methods (Udaipurwala and Russell, 2002), and there is a need establish the extent to which knowledge management techniques can be effectively applied to CPS. This paper aims to develop a knowledge management model for capturing and reusing experiential knowledge to guide CPS decisions. A suitable approach for managing CPS knowledge is first identified. This is then followed by identifying the knowledge to be captured for CPS Finally, the mechanism for the retrieval and reuse of knowledge is elucidated for guiding CPS decisions.

\section{SELECTION OF KNOWLEDGE MANAGEMENT APPROACH}

The principle role of a knowledge management system is to capture and disseminate relevant knowledge. However, to enhance performance and to increase the chance of project success (Ofek and Sarvary, 2001; Kamara et al., 2002; Mansell, 2002), it is desirable to create new (better) solutions based on the knowledge thus far accumulated (cf: O'Leary, 1998). This requires the incorporation of reasoning and justification mechanisms (Hsieh et al., 2002). More importantly, the distinctive characteristics of CPS should be considered when selecting an approach for managing knowledge. These include: (i) the existence of diverse characteristics, requirements and conditions unique to the project; and (ii) an implicit interrelationship of the PSPs that describe the distinctive characteristics of the client, project and external environment.

The notion of framing "a contextualised piece of knowledge representing an experience" in a case (Kolodner, 1993, p.13) has rendered the CBR approach an attractive option for managing CPS knowledge, as recalling incident (i.e. constraint $₫$ solution $₫$ outcome) by case and reusing/adapting the solution of a similar case to suit the current situation is a frequently applied approach to solving practical problems (Aamodt, 1990; Barletta, 1991). Furthermore, by storing and retrieving cases in a mega-knowledge format (Aamodt and Plaza, 1994), CBR approaches should have a high potential for modelling the procurement selection decisions under a complex dynamic environment. 


\section{KNOWLEDGE TO BE CAPTURED}

To identify a process of CPS and knowledge required for supporting CPS decisions, semi-structured interviews were conducted with five experts with experience in this domain. The experts interviewed included managers of major client (including four governmental and one private) organisations in Australia. The results of the interviews indicated that the CPS process involved: (i) the formulation of PSP's; and (ii) the selection of an appropriate procurement system, and the knowledge required is different for each of these two stages.

\section{Knowledge Pertinent to PSPs Formulation Stage}

Since the aim of this stage is to establish a set of PSPs that would adequately represent the characteristics and requirements of the client, project and external environment (cf: Ambrose and Tucker, 1999), the knowledge required should be composed of both the problem and solution parts (Figure 1). The problem part should encapsulate the knowledge regarding: (i) the features of all existing projects for which various procurement systems were employed; (ii) the characteristics and needs of the clients; and (iii) the properties of the external environment that encountered by clients. Luu et al. (2003) summarised the factors that could influence the choice of the PSPs (Table 1). The solution part focuses on the knowledge pertinent to the PSPs, their weightings adopted in previous CPS evaluations, and reasons/justifications for previous solutions.

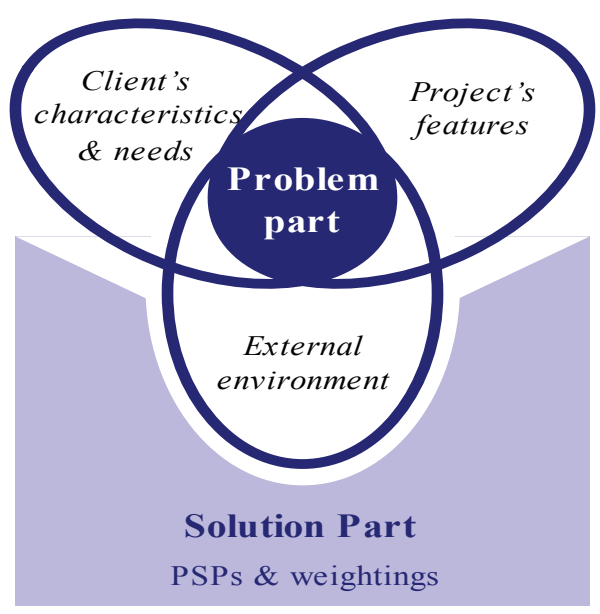

Figure 1: Knowledge pertinent to PSPs formulation stage

\begin{tabular}{|c|c|c|}
\hline Client's characteristics \& needs & Project's features & External environment \\
\hline $\begin{array}{l}\text { Experience } \\
\text { Experience level of the client and his } \\
\text { or her organisation in the construction } \\
\text { domain, i.e. primary experienced, } \\
\text { secondary experienced } \\
\text { Type } \\
\text { Nature of the client's organisation in } \\
\text { reference to this particular project; } \\
\text { i.e. government bodies, investors, } \\
\text { developers, occupiers, etc. } \\
\text { In-house capability } \\
\text { Client's capability to use their own } \\
\text { resources in this particular project and } \\
\text { client's wishes to be directly involved in } \\
\text { this particular project. } \\
\text { Time limitation } \\
\text { Does the client require any restrictions } \\
\text { on time in this particular project? } \\
\text { Financial limitation } \\
\text { Does the client have any restrictions on } \\
\text { finance in this particular project? }\end{array}$ & $\begin{array}{l}\text { Project scale } \\
\text { Size of the project measured by its } \\
\text { estimated value } \\
\text { Building type } \\
\text { Type of the proposed building in this } \\
\text { particular project, i.e. commercial, } \\
\text { residential, industrial, etc. } \\
\text { Construction type } \\
\text { Type of the construction method in } \\
\text { this project, i.e. new construction, } \\
\text { refurbishment, combination of both } \\
\text { Site conditions } \\
\text { Relative assessment of conditions of } \\
\text { various site factors having impact on } \\
\text { the project procurement such as site } \\
\text { access and egress, foundations, etc. } \\
\text { Site location } \\
\text { Geographical location of site }\end{array}$ & $\begin{array}{l}\text { Market competition } \\
\text { Level of competition in the market with } \\
\text { regards to this project } \\
\text { Environmental impact } \\
\text { The impact of natural environment on } \\
\text { the project procurement process, i.e. } \\
\text { inclement weather, natural disasters, } \\
\text { etc. } \\
\text { Cultural impact } \\
\text { The impact of cultural differences on } \\
\text { the project procurement process } \\
\text { Political impact } \\
\text { The impact of political activities on the } \\
\text { project procurement process } \\
\text { Resource availability } \\
\text { i) Availability of contractors and } \\
\text { subcontractors who have enough } \\
\text { expertise to fulfil the requirements of } \\
\text { project specifications } \\
\text { ii) Availability of technology to carry } \\
\text { out a certain construction techniques } \\
\text { required by the project specifications } \\
\text { iii) Availability of materials as required } \\
\text { in the project specifications }\end{array}$ \\
\hline
\end{tabular}

Table 1: Factors influencing the formulation of PSPs 
Knowledge Pertinent to Procurement Selection Stage

During the procurement selection stage, the set of PSPs formulated during the preceding stage need to be used to establish the relevance and appropriateness of each procurement system. In addition to comparing the benefits and weaknesses of each procurement system against the predominant characteristics and requirements of the client, project and environment, decisionmakers have to recall the outcomes of previous similar examples. Therefore, the knowledge related to this stage should consist of three major components - problem, solution and outcome
(Figure 2). The problem part should represent the knowledge of the PSPs used in the previous CPS processes - these PSPs being related to time certainty, cost certainty, speed, flexibility, responsibility, complexity, price competition, risk allocation and quality as illustrated in Table 2 (see Sidwell, 1984; NEDO, 1985; Nahapiet and Nahapiet, 1985; Skitmore and Marsden, 1988; Walker, 1989; Hughes, 1989; Masterman, 1992; Masterman and Gameson; 1994; Love et al., 1998; Rowlinson and McDermott, 1999; Ambrose and Tucker, 1999; Alhazmi and McCaffer, 2000; Chen, 2000; Kumaraswamy and Dissanayaka, 2001).

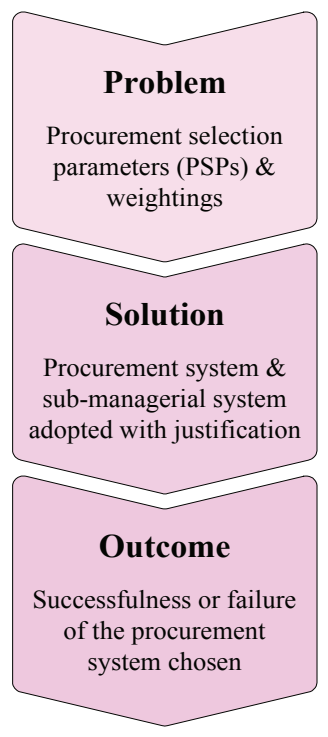

Figure 2: Knowledge pertinent to procurement selection stage

\begin{tabular}{ll}
\hline PSPs & Description \\
\hline Speed $\mathrm{a}, \mathrm{d}, \mathrm{e}, \mathrm{f}$ & $\begin{array}{l}\text { Speedy procurement process, e.g. a desire to have the project completed as soon as } \\
\text { possible. }\end{array}$ \\
\hline Cost certainty $\mathrm{b}, \mathrm{c}, \mathrm{d}, \mathrm{e}, \mathrm{f}$ & $\begin{array}{l}\text { Price and the stipulated time and knowledge of how much the client has to pay at each } \\
\text { period during the construction phase. A reduction in unanticipated extra cost over-run }\end{array}$ \\
\hline Time certainty b,c,d,ef & $\begin{array}{l}\text { Degree of certainty that the project will be completed on the date, which is agreed by client } \\
\text { and contractor when signing the contract. A reduction in unanticipated extra time over-run. }\end{array}$
\end{tabular}

Flexibility a,b,d,e,f

Ability to accommodate design changes during both design and construction periods

Responsibility a,b,c,d,e,f An involvement in, and a need to be kept informed about, the project throughout its life

Complexity a,d,e,f Client may specify innovative design/ high technology building and require particular subcontractor, or constructability analysis

Quality level ${ }^{a, d, e, f} \quad$ Contractor's reputation, aesthetics and confidence in design.

A building which reflects the clients activities and image

Risk allocation/avoidance ${ }^{\text {a,de,f }} \quad$ A wish to identify risks and uncertainties during the procuring process

Price competition a,c,d,e,f Covering such issues as value for money, maintenance, costs and competitive tendering.

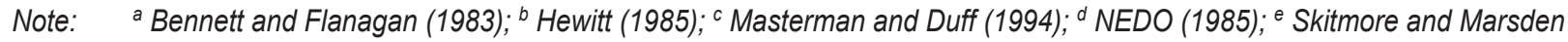
(1988); ${ }^{f}$ Singh (1990)

Table 2: Common PSPs 
The knowledge in the solution part should, however, contain the procurement system used, and its sub-managerial systems, such as the tendering method and contractual arrangement, etc. As for the outcome knowledge, feedback detailing the successfulness of the procurement system adopted in a particular project would be beneficial. According to Kumaraswamy and Dissanayaka (2001), the successfulness of a construction project can be measured in terms of the reduction in capital and lifecycle costs, greater cost and time certainty, shorter procurement duration, better quality, more effective and efficient decision-making and communication, and minimisation of disputes. It would be useful if both successful and unsuccessful construction projects are recorded in the knowledge-base, as the failure examples can alert decision-makers to the potential problems that may occur should a particular procurement system be used under certain constraints (cf: Sycara and Miyashita, 1994).

\section{RETRIEVING AND REUSING KNOWLEDGE FOR DECISION SUPPORT}

The basic procedure of retrieving and reusing CPS knowledge through the CBR engine is illustrated in Figure 3. In essence, the underlying mechanism of CBR is to retrieve "similar" historic cases and knowledge based on the characteristics of the new scenario. As with any other real-world domains, it is difficult to have a historic construction project that fully resembles the current case. Therefore, not only is it necessary to establish whether the new and retrieved cases are similar enough to provide decision-makers with the relevant and reliable knowledge, but it is also desirable to have a high level of flexibility when the cases/knowledge are retrieved and reused. Therefore, during both the PSPs formulation and procurement selection stages, cases are retrieved according to a similarity matching concept known as nearest neighbour retrieval. Once the new solution is adopted, the knowledge is stored automatically for future use in the case repository.

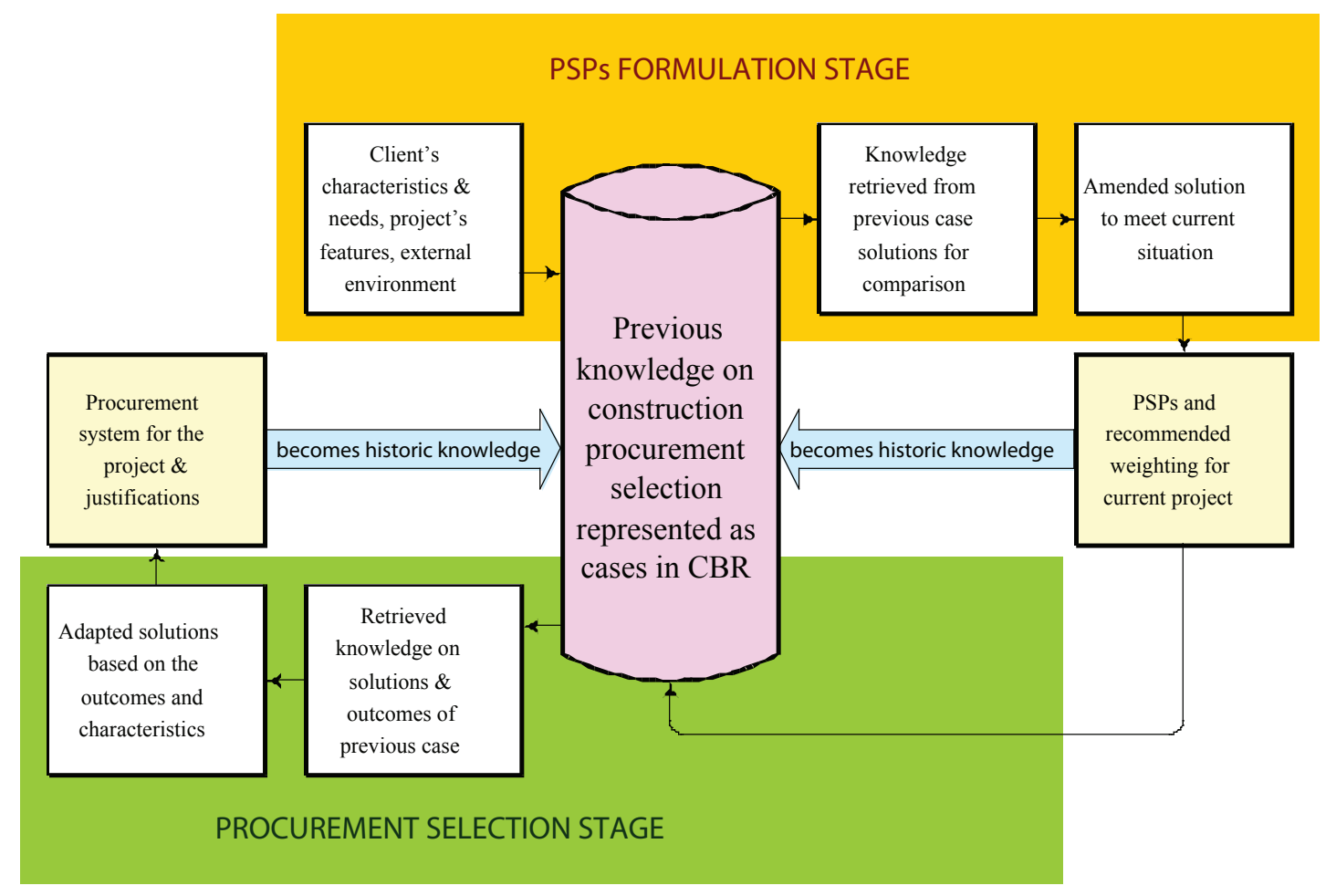

Figure 3: Basic mechanism of retrieving and reusing the stored knowledge

\section{PSPs Formulation Stage}

An interface, as shown in Figure 4, is designed to capture the characteristics and requirements of the client, project and environment pertinent to a new project. To minimise data inputting time and errors, a list of possible values is provided through a pull down menu against each input item. For instance, the decision-maker can classify his/her organisation as a "primary inexperienced" or "secondary experienced" client (Figure 5). The system also accepts blank entries when the decision-maker is unsure of the most appropriate answer to describe certain client/ project characteristics.

The predominant characteristics of all stored cases can be compared with the data entered by the decision-maker, and the similarity of each attribute computed based on the following formula:

Similarity Score $=$ Attribute Score $x 100$ Maximum Presented Score

Where: $\quad$ Attribute score $=$ the sum of matching scores between attribute values of the stored and presented cases.

Maximum presented score $=$ attribute score when the stored case is exactly identical to the presented case. 


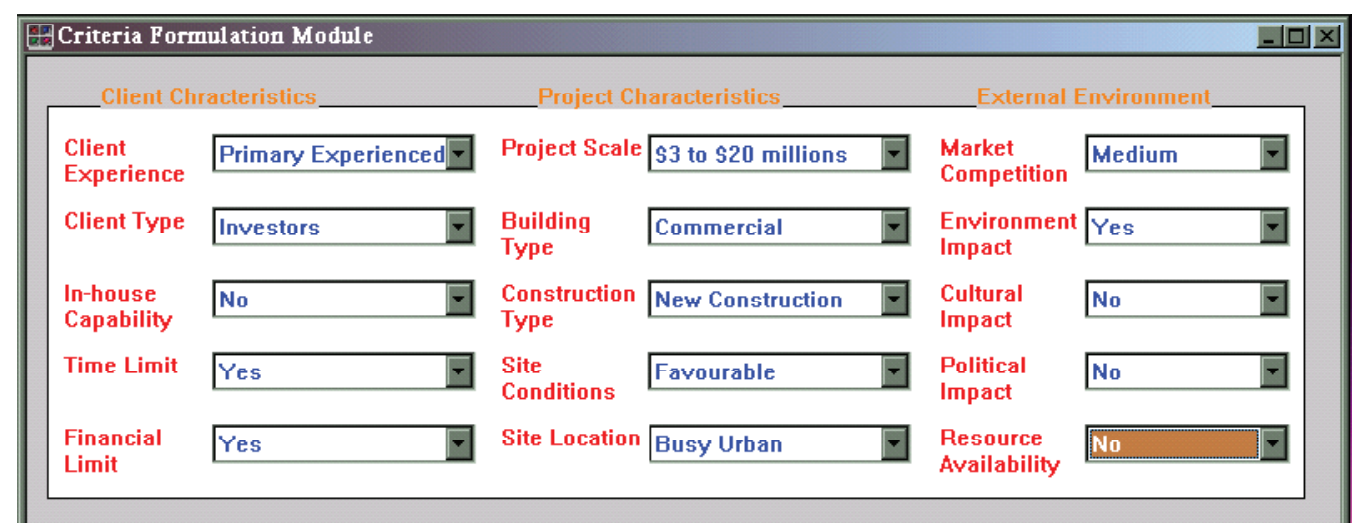

Figure 4: Interface for extracting the characteristics of client, project and environment

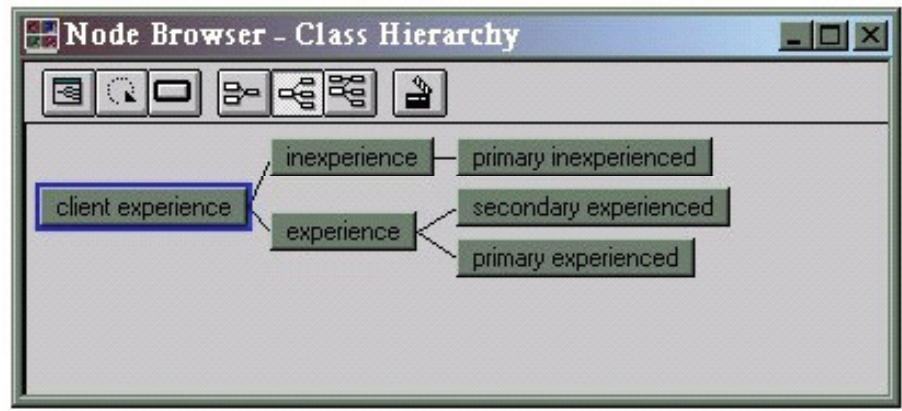

Figure 5: Possible values for the attribute of "client experience"

Once the individual scores are generated for all attributes, a final similarity score for each case (Figure 6) can be derived for cases to be rank-ordered. The five cases with the highest similarity scores are then presented through the user interface for consideration. As shown in Figure 6, preliminary information about the most similar historic case, i.e. the case features and client's satisfaction, are highlighted. Depending upon the project performance, the decisionmaker can decide whether to further examine the particulars of the most similar case or to browse the preliminary information for the next most similar case. Further details on the PSPs used (Figure 7) can be obtained by pressing the "view details" button. If the knowledge of the most similar case is applicable to the current project, the "accept recommendation and move to the next module" button (Figure 7) can be checked and a screen as shown in Figure 8 presented to initiate the procurement selection stage.

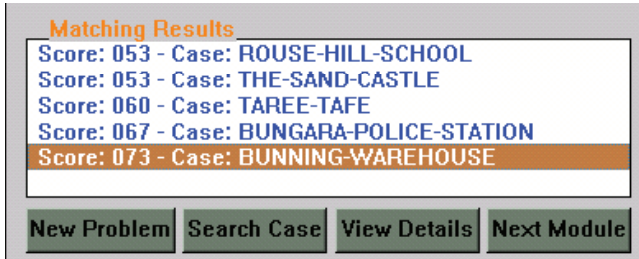

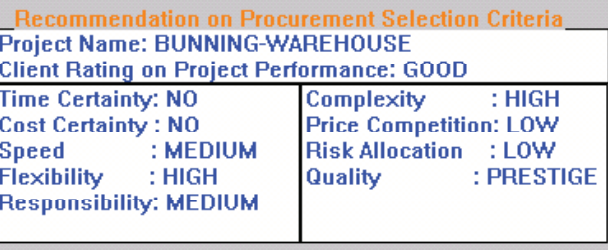

Figure 6: Cases retrieved during PSPs formulation stage

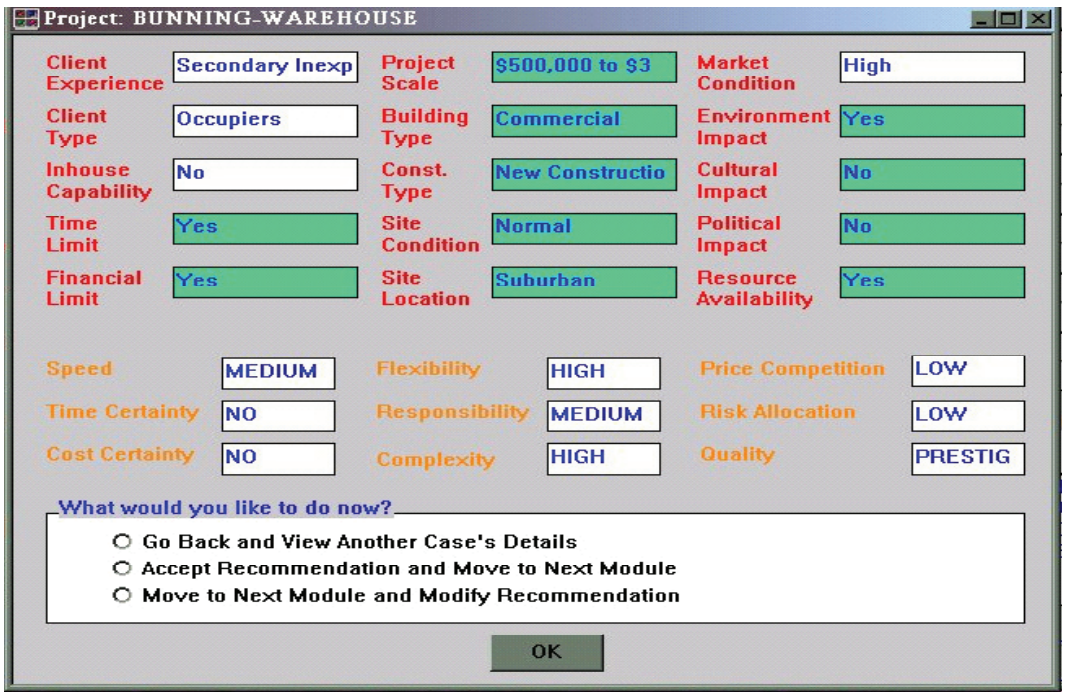

Figure 7: Solution adopted in the previous case during PSPs formulation stage

36 The Australian Journal of Construction Economics and Building [Vol 5, № 1] 


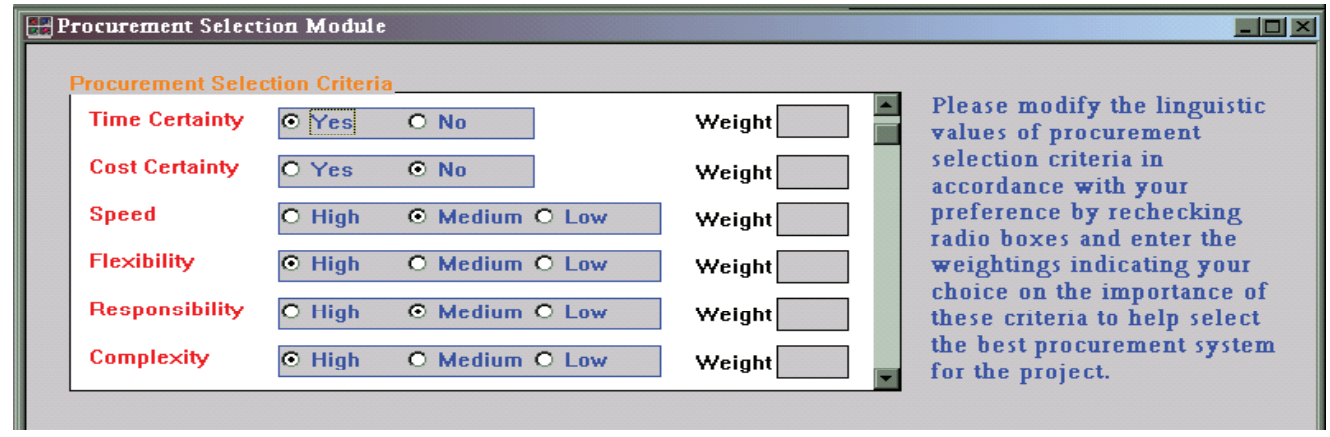

Figure 8: Interface for altering the PSPs and weightings at procurement selection stage

\section{Procurement Selection Stage}

The knowledge extracted through the preceding stage provides an initial but valuable guideline to the decision-maker for establishing which PSPs should be used for the procurement selection stage. Nevertheless, the decision-maker might still wish to modify the PSPs to reflect the inherent discrepancies between the new and old cases; and this can be achieved by making the necessary adjustments to any of the items as illustrated in Figure 8. Like the preceding stage, the nearest neighbour retrieval approach is used to compute the similarity score for each case based upon the input features. The decision-maker can also request the system to display the details of the most similar case for further evaluation. As depicted in Figure 9, knowledge regarding the procurement system, tendering method, contract type, and client's overall rating is disseminated through the user interface. Those not familiar with the proposed procurement option can simply click on the "system details" button to view the features, advantages and disadvantages of the recommended procurement system. When users are convinced that the solution and possible outcomes are suitable for the current project, they can adopt the previous solution for the new project.

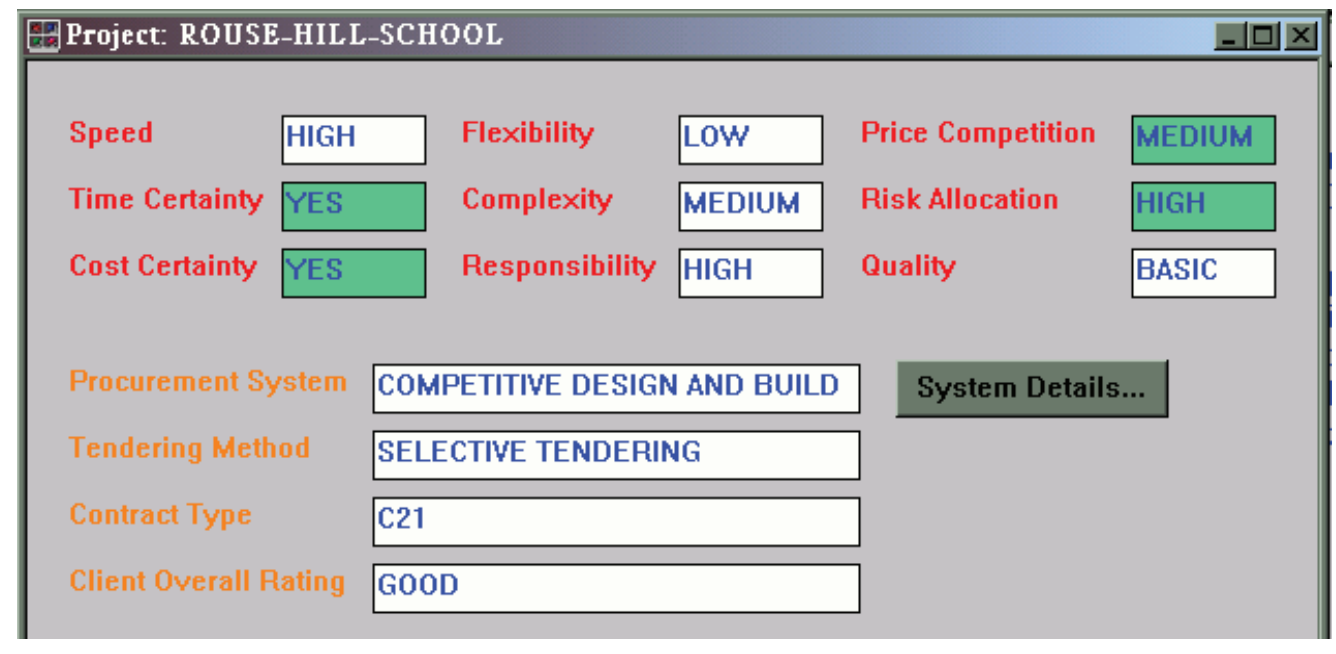

Figure 9: Solution and outcome of the retrieved cases at procurement selection stage

However, since the intrinsic characteristics and requirements of the new and retrieved cases may still differ slightly, modifications to the historic solutions would be inevitable. As a result, a technique known as critic-based adaptation (Brown and Lewis, 1993) is built-in to allow users to go through the retrieved solutions sequentially and modify the solution corresponding to a particular step to suit the predominant situation. The "adaptation strategy" section in Figure 10 outlines all the details used in arriving at the recommended solution, and these include the details of the new and historic cases. Driven by pre-determined rules/formulae, and based on the extent of difference between the new and retrieved cases, the model will prompt the user to consider modifying certain PSP(s), such as "speed" as in the case illustrated in Figure 10 (refer to the "Yes/No" status in the "to be adapted" column). By clicking the "actions to improve" button, the user is presented with different alternatives to modify the solution and the revised recommendation is made to the decisionmaker for final consideration. This not only allows for 'what-if' scenarios, but also provides a more relevant and reliable solution to improve the chance of project success. 


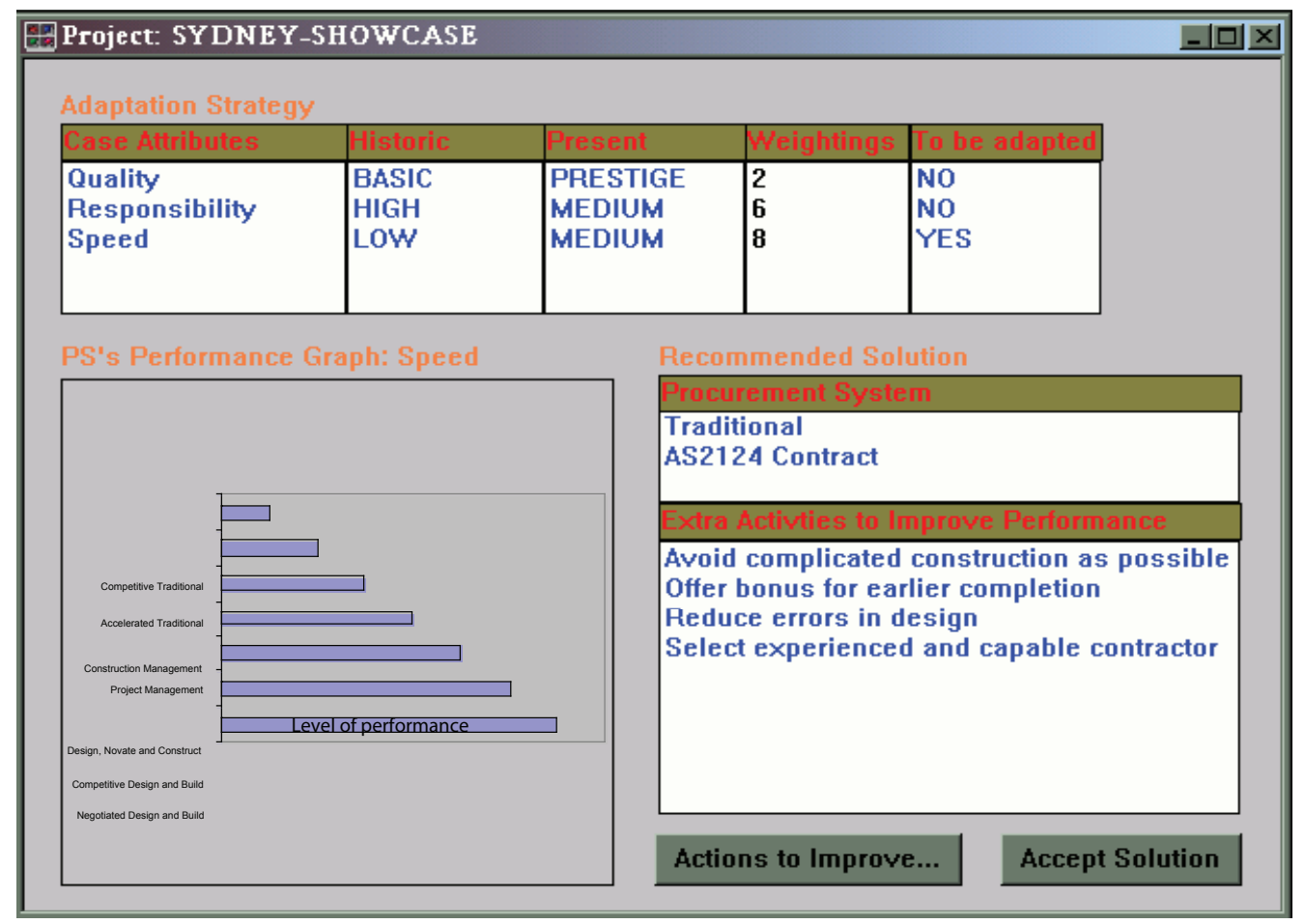

Figure 10: Critic-based adaptation at procurement selection stage

\section{CONCLUSIONS}

This paper has examined some methods for capturing and reusing CPS knowledge. As the characteristics and requirements of the client, project and external environment differ from one project to another, and therefore give a diverse continuum of procurement options, the approach to managing the knowledge must be very flexible. CBR is considered a suitable approach for storing CPS knowledge, as not only can it retrieve close matching cases based on the nearest neighbour retrieval mechanism, but it can also allow users to adapt the solution of the retrieved case to suit the predominant characteristics of the current project.

Knowledge to be captured will be specific to the two main CPS stages. During the PSPs formulation stage, the knowledge related to the client's characteristics and needs, project features, and external environment (the problem part) as well as the PSPs and weightings (the solution part) will be encapsulated. Knowledge pertinent to the procurement selection stage includes the features of the PSPs and weightings (the problem part). Furthermore, the procurement option, tendering method, and contractual arrangement (the solution part) together with the client's satisfaction (the outcome part) should also be considered. Clients and consultants should consider developing and maintaining a knowledge repository for CPS to capture useful knowledge such as factors governing the selection of procurement method, the reasons for selecting a procurement approach, as well as the project outcomes caused by the procurement method selected. Such knowledge would serve as a reference to clients and consultants when selecting a procurement method for a project of similar characteristics and requirements.

A prototype knowledge management model for CPS was developed in accordance with the CBR concept, and the functionality of the model has been elucidated in this paper. The prototype shows that PSPs and weightings can be formulated by referring to the solution of similar historic cases, and that this knowledge can then be used for retrieving a project with similar characteristics to the current one. By examining the procurement option adopted by the most similar project (and its outcome), decision-makers would have an idea as to which procurement system to opt for (and its potential outcome). The provision of an adaptation strategy also allows for 'what-if' scenarios, which would be very useful to decision-makers in an increasingly uncertain construction environment.

\section{REFERENCES}

Aamodt, A. (1990), 'Knowledge-intensive case-based reasoning and sustained learning', in proceedings of the ECAI-90, Ninth European Conference on Artificial Intelligence, August 6-10, Stockholm, Sweden, L.C. Aiello (ed.), Pitman Publishing, pp.1-6.

Aamodt, A. and Plaza, E. (1994), 'Case based reasoning: foundational issues, methodological variations and system approaches', Artificial Intelligence Communication, vol.7, pp.3959.

Alhazmi, T. and McCaffer, R. (2000), 'Project procurement system selection model', Journal of Construction Engineering and Management, ASCE, vol.126, no.3, pp.176-184.

Ambrose, M.D. and Tucker, S.N. (1999),' Matching a procurement system to client and project needs: a procurement system evaluator', in proceedings of Customer Satisfaction: A Focus for Research and Practice in Construction, P.A. Bowen and R.D. Hindle (eds.), Cape Town, South Africa, University of Cape Town, pp.280-288.

Barletta, R. (1991), 'An introduction to case-based reasoning', Al Expert, August, pp.43-49.

Bennett, J. and Flanagan, R. (1983), 'For the good of the client', Building, 1st April, pp.26-27. 
Bennett, J. and Grice, A. (1990), Procurement Systems for Building, Quantity Surveying Techniques - New Directions, BSP Professional Books, Oxford, UK.

Brandon, E.S., Basden, A. and Hamilton, I.W. (1988), Expert System: The Strategic Planning of Construction Projects, Royal Institution of Chartered Surveyors and University of Salford, UK.

Brown, S.J. and Lewis, L.M. (1993), 'A case-based reasoning solution to the problem of redundant resolutions of nonconformances in large-scale manufacturing', in Innovative Applications of Artificial Intelligence 3, R. Smith \& C. Scott (eds.), AAAI Press, pp.121-133.

Chan, A.P.C., Ho, D.C.K. and Tam, C.M. (2001), 'Design and build project success factors: multivariate analysis', Journal of Construction Engineering and Management, ASCE, vol.127,no.2, pp.93-100.

Chen, S.E. (2000), Project Performance: A Complexity Perspective, Unpublished PhD thesis, University of Newcastle, Australia.

Cheung, S.O., Lam, T.I., Wan, Y.W. and Lam, K.C. (2001), 'Improving objectivity in procurement selection', Journal of Management in Engineering, ASCE, vol.17, no.3, pp.132-139.

Franks, J. (1990), Building Procurement Systems - A Guide to Building Project Management, Chartered Institute of Building, Ascot, UK.

Hamilton, I.W. (1987), 'Developing expert systems for management applications', Building Cost Modeling and Computers, P.S. Brandon (ed.), E \& FN Spon, London, pp.441451.

Hewitt, R.A. (1985), The procurement of buildings: proposals to improve the performance of industry, report to the College of Estate Management, UK.

Hsieh, C.T., Yang, H. and Lin, B. (2002), 'Roles of knowledge management in online procurement systems', Industrial Management \& Data Systems, vol.102, no.7, pp.365-370.

Hughes, W. (1989), 'Identifying the environments of construction projects', Construction Management and Economics, vol.7, pp.29-40.

Ireland, V. (1985), 'The role of managerial actions in cost, time and quality performance of high rise commercial building projects', Construction Management and Economics, vol.3, no.1, pp.59-87.

Kamara, J.M., Anumba, C.J. and Carrillo, P.M. (2002), 'A CLEVER approach to selecting a knowledge management strategy', International Journal of Project Management, vol.20, no.3, pp.205-211.

Kolodner, J. (1993), Case-Based Reasoning, Morgan Kaufmann Publishers, San Mateo, CA, USA.

Kumaraswamy, M. and Dissanayaka, S. (2001), 'Developing a decision support system for building project procurement', Building and Environment, vol.36, no.3, pp.337-349.

Love, P.E.D., Skitmore, R. M. and Earl, G. (1998), 'Selecting a suitable procurement system for a building project', Construction Management and Economics, vol.16, pp.221-233.

Luu, D.T., Ng, S.T. \& Chen, S.E. (2003), 'Parameters governing the selection of procurement system - an empirical survey', Engineering, Architectural and Construction Management, (in press).

Mansell, R. (2002), 'Constructing the knowledge base for knowledge-driven development', Journal of Knowledge Management, vol.6, no.4, pp.317-329.

Masterman, J.W.E. (1992), An Introduction to Building Procurement Systems, E\& FN Spon, London.

Masterman, J.W.E. and Duff, A.R. (1994), 'The selection of building procurement systems by client organzations', in proceedings of the 10th Annual ARCOM Conference, Loughborough University of Technology, Association of Researchers in Construction Management, Leicestershire, 14-16 September, R.M. Skitmore and M. Betts (eds.), vol.2, pp.650-659.

Masterman, J.W.E. and Gameson, R. (1994), 'Client characteristics and needs in relation to their selection of procurement systems', in proceedings of East Meets West - Procurement Systems Symposium, CIB Publication 175, 4-7 December, Hong Kong, S. Rowlinson (ed.), pp.79-87.

Mohsini, R.A. (1993), 'Knowledge-based design of projectprocurement process', Journal of Computing in Civil Engineering, ASCE, vol.7, no.1, pp.107-122.

Naoum, S.G. (1994), 'Critical analysis of time and cost of management and traditional contracts', Journal of Construction Engineering and Management, ASCE, vol.120, no.4, pp.687-705.

Nahapiet, H. \& Nahapiet, J. (1985), The Management of Construction Projects - Case Studies from the UK \& USA, Chartered Institute of Building, Ascot, UK.

NEDO (1985), Thinking About Building, National Economic Development Office, HMSO, London, UK.

Ofek, E. and Sarvary, M. (2001), 'Leveraging the customer base: creating competitive advantage through knowledge management', Management Science, vol.47, no.11, pp.14411456.

O'Leary, D.E. (1998), 'Knowledge-management systems: converting and connecting', IEEE Intelligent Systems \& Their Applications, vol.13, no.3, pp.30-33.

Rowlinson, S. and McDermott, P. (1999), Procurement Systems: A Guide to Best Practice in Construction, E \& FN Spon, UK.

Rwelamila, P.D. and Meyer, C. (1999), 'Appropriate or default project procurement systems', Cost Engineering, AACE, vol.41, no.9, pp.40-44.

Sharif, A. and Morledge, R. (1994), 'The procurement systems model by the functional approach', in proceedings of the 10th Annual ARCOM Conference, Loughborough University of Technology, Association of Researchers in Construction Management, Leicestershire, 14-16 September, R.M. Skitmore \& M. Betts (eds.), vol.2, pp.660-671. 
Sidwell, A. C. (1984), 'An evaluation of management contracting', Construction Management and Economics, vol.1, pp.47-55.

Silver, C. (2000), 'Where technology and knowledge meet', Journal of Business Strategy, vol.21, no.6, pp.28-33.

Singh, S. (1990), 'Selection of appropriate project delivery system for building construction projects', in proceedings of the CIB-90

Building Economics and Construction Management, University of Technology Sydney, pp.469-480.

Skitmore, R.M. and Marsden, D.E. (1988), 'Which procurement system? Towards a universal procurement selection technique', Construction Management and Economics, vol.6, pp.71-89.

Storey, J. and Barnett, E. (2000), 'Knowledge management initiatives: learning from failure', Journal of Knowledge Management, vol.4, no.2, pp.145-156.

Sycara, K. and Miyashita, K. (1994), 'Learning from failure in case-based schedule repair', IEEE, vol.3, pp.122-131.

Tah, J.J.M. and Carr, V. (2001), 'Towards and framework project risk knowledge management in the construction supply chain', Advances in Engineering Software, vol.32, no.10-11, pp.835-846.

Udaipurwala, A. and Russell, A.D. (2002), 'Computer-assisted construction methods knowledge management and selection', Journal of Civil Engineering, vol.29, no.3, pp.499-516.

Walker, A. (1989), Project Management in Construction, Granada Publications, UK.

Ward, S.C., Curis, B. and Chapman, C.B. (1991), 'Objectives and performance in construction projects', Construction Management and Economics, vol.9, pp.343-353. 